\title{
A Fixed Anode Tube with a Very Fine Focus Made with Autobiased Electron Beam
}

Its Application to Enlargement Radiography* (Studies on Enlargement Radiography. Ist Report)

By

\author{
Shinji Takahashi and Kihachiro Komiyama \\ (高橋信次) (小宮山喜八瞋) \\ From the Department of Radiology, University Hospital, \\ Nagoya \\ and Masamichi Tanaka \\ (昍中正道) \\ From the Toshiba Electric Company Ltd. Kawasaki
}

(Received for publication, September 13, 1954)

The very fine focus rotating anode tube has recently widened the clinical radiographic investigation. ${ }^{12 / 3)}$ In this tube, the small sized heating filament is set deep in the focusing cap after the principle of Burgers $e t$ al. ${ }^{4}$ device. The focal spot is entitled by the manufacturer as 0.3 $\mathrm{mm}$. in size. When this tube is used in enlargement radiography, the enlargement ratio may be twice life size, at the largest.

In order to obtain a more fine focal spot than that of the usual one, the electron beam, emitted from the heating filament, was made narrow by the principle of bias phenomena. For this purpose, an X-ray tube was reconstructed to a three electrode vacuum tube. Three electrodes consisted of a terminal of the wire from the focusing cap and two terminals of the filament heating circuit.

As a radiation source a line focus $(4 \times 12 \mathrm{~cm}$. in size $)$ of a fixed anode tube of $6 \mathrm{~kW}$. was used. The heating filament was made spiral with a tungsten wire of $0.2 \mathrm{~mm}$. in diameter. The spiral itself was measured $12.0 \mathrm{~mm}$. in length and $1.20 \mathrm{~mm}$. in diameter.

The lead wire of the focusing cap and that of the heating filament were isolated from each other so as to be safe from at least three thousand voltages. When the lead wire from the focusing cap in this tube was connected directly with the X-ray tube circuit and at the same time the one from the tube filament was connected indirectly, as was illustrated in Fig. 1, with a resistance $\mathrm{R}$ in series to the same circuit, the electric potential

* Read at the 17th Meeting of Hirosaki Medical Association held on Dec. 19, 1953. 
of the tube filament was A.R higher than the one of the focusing cap.

Under the principle of autobias of the electron beam emitted from the filament, the focal spot, diminished its size with the increase of the resistance $R$, and became, finally, the optimum minimum, a line as shown in Fig. 2. The focal spot of this tube was roentgenographed in life size with a pin hole camera of $0.12 \mathrm{~mm}$. in aperture. This linear focal spot was lessened effectively to a point radiation source when the surface of the target was inclined to the vertical line from $1^{\circ}$ to $2^{\circ} 50^{\prime}$.

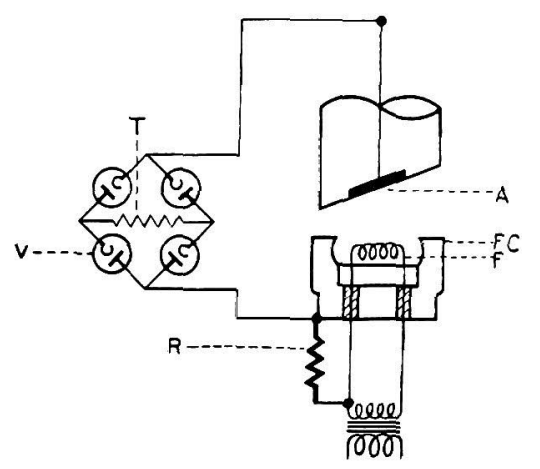

Fig. 1. Schema of an X-ray tube reconstructed to a three electrode vacuum tube. $\mathrm{T}:$ Main transformer. $\mathrm{V}:$ Vulve. A: Target of X-ray tube. Fc: Focusing cap. F : Heating filament. R: Resistance.

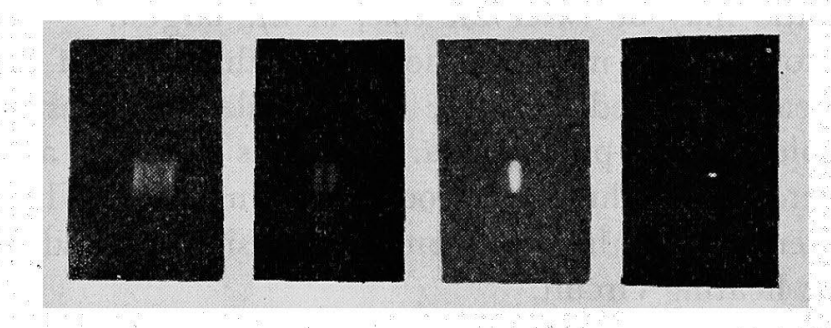

Fig. 2. Focal spot photographed with a pin hole camera. Focal spot diminishing its size with increase of the resistance. (From left to right)

In order to know the optimal difference of electric potential between the focusing cap and the heating filament, wires of a $0.06 \mathrm{~mm}$. in diameter were arranged parallel to each other at intervals of a $0.06 \mathrm{~mm}$., and this model of wires was roentgenographed with this bias tube in twice, thrice, five times, ten times and twenty times enlargements. When it was 0.06 $\mathrm{mm}$., the X-ray image of wires gave the same number as the subject itself even in the roentgenogram of twenty times enlargement (Fig. 3).

This model experiment enabled us to obtain the real size of the focal 
spot. In Figure 4, the following abbreviation represent respectively that, $a$ is the size of the focal spot, $b$ is the diameter of the wire as well as the breadth of gaps between wires, $m$ is the distance between the focal spot and the wires, $\mathbf{n}_{1}$ is the first place where the penumbra of wires crosses, $\mathrm{n}_{2}$ the second place of that, and $\mathrm{n}_{3}$ the third place of that. When $a$ is larger than $2 b$ in size, the wires are imaged at the position of $n_{1}$ in the same number as the number of wires. Whereas, at the position of $n_{2}$, the wires are not imaged as parallel lines, but are imaged mixed homogeneously. At the position of $n_{3}$, the wires are imaged as parallel lines. The number of wires imaged, however, is not the same as the original number of wires themselves, but is increased. When the size of $a$ is equivalent to $2 b$ or smaller than that, the wires are imaged always in the same number of lines as the original one of the wires themselves.

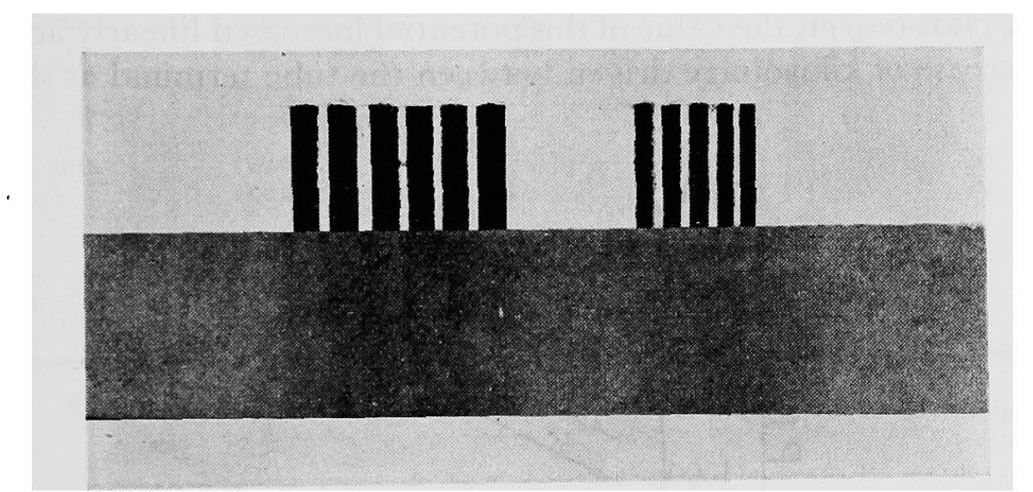

Fig. 3. Enlargement radiograpm of wires arranged parallel to each other at intervals of equivalent distance as its diameter. (Enlargement ratio: 20 times) left: Wires of $0.06 \mathrm{~mm}$ in diameter. right: Wires of $0.1 \mathrm{~mm}$. in diameter. top: Shema.

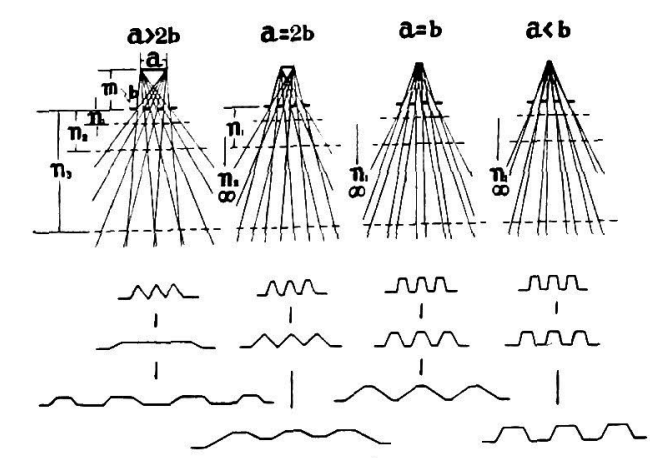

Fig. 4. Schema of occurance of penumbra. a : Size of focal spot. b: Diameter of wire. $m$ : Distance between the focal spot and wire. $\mathrm{n}_{1}$ : First place where the penumbra of wires crosses. $\mathrm{n}_{2}$ : Second place of that. $n_{3}$ : Third place of that. 
These facts were actually proved with the model experiment. The figure at the left of Fig. 4 ( $a>2 b$ ) reveals the following geometrical relation: $\frac{a}{2 b}=\frac{m+n_{1}+n_{2}}{n_{1}+n_{2}}$. Here, the value of $2 b$ is $0.12, m$ is 1 and $n_{1}+n_{2}$ is larger than 19. From this consideration we arrived at the conclusion that the focal spot of our X-ray tube was, at least, not larger than 0.126 $\mathrm{mm}$.

The optimum electric potential between the focussing cap and the heating filament are variable according not only to kilovoltage to be driven, but also to the tube character to be used.

Testing three different X-ray tubes of $6 \mathrm{~kW}$., delivered from the same manufacturer, we found that the optimum electric potential was 1500 voltage, 1700 voltage or 2000 voltage respectively at 50 kilovoltage of tube terminal. Moreover, the value of this potential increased linearly according to the increase of kilovoltage driven between the tube terminal as shown in Fig. 5.

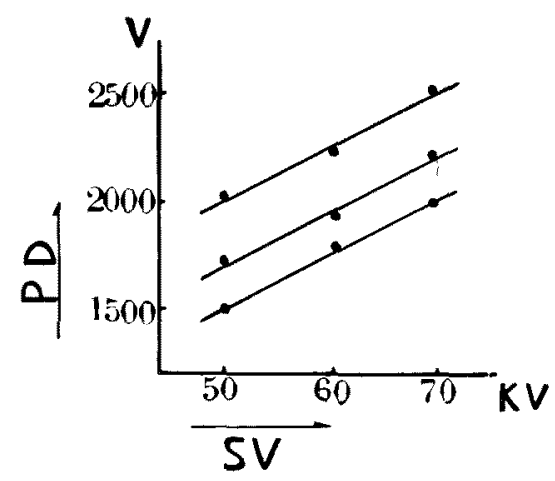

Fig. 5. Diagram of electric potential between the focusing cap and the heating filament. SV : Potential at the tube terminal. PD : Potential between the focusing cap and the filament.

By means of this X-ray tube we have taken enlargement radiogram of any part of the body as routine clinical work now. The roentgenographic conditions used are shown in the Table I.

Figure 6 illustrates a three times enlarged radiogram of the third lumbar spine of a healthy adult taken anteroposteriorly. The bony contour of the spine is imaged sharp, and the bony trabecullae in the body are visualized very fine in the structure.

Our X-ray tube has been used for exposure of 930 times, of which the roentgenographic condition is detailed in Tables I and II.

After the exposure of 110 times a faint white line was detected on the smooth surface of the target. This line, placed at the center of two edges 


\section{TAB LE I}

\section{Our Factors in Enlargement Radiography}

FS: Intensifying screen. Intensifying coef. of 20. Sharpness coeff. of 0.56 (Spiegler a. Rudinger)., MS : Intensifying screen. Intensifying coef. of 35. Sharpness coeff. of 0.49 (Spiegler a. Rudinger). SS : Intensifying screen. Intensifying coef. of 70 . Sharpness coeff, of 0.42 (Spiegler a. Rudinger).

\begin{tabular}{|c|c|c|c|c|c|c|}
\hline & $\begin{array}{c}\text { Enlargement } \\
\text { ratio }\end{array}$ & $\begin{array}{c}\text { Focus-fllm } \\
\text { distance }\end{array}$ & $\begin{array}{l}\text { Screen } \\
\text { used }\end{array}$ & $\mathrm{kV}$ & $\mathrm{mA}$ & Sec. \\
\hline Elbow joint & $\begin{array}{l}\text { twice } \\
\text { three times }\end{array}$ & $\begin{array}{l}60 \\
90\end{array}$ & $\begin{array}{l}\text { FS* } \\
\text { FS }\end{array}$ & $\begin{array}{l}50 \\
50\end{array}$ & $\begin{array}{l}30 \\
30\end{array}$ & $\begin{array}{l}0.2 \\
0.4\end{array}$ \\
\hline Head & $\begin{array}{l}\text { twice } \\
\text { three times }\end{array}$ & $\begin{array}{r}90 \\
135\end{array}$ & $\begin{array}{l}\text { FS } \\
\text { FS }\end{array}$ & $\begin{array}{l}70 \\
70\end{array}$ & $\begin{array}{l}30 \\
30\end{array}$ & $\begin{array}{l}1.0 \\
2.0\end{array}$ \\
\hline Lung (p.a.) & $\begin{array}{l}\text { twice } \\
\text { three times } \\
\text { three times }\end{array}$ & $\begin{array}{l}150 \\
150 \\
150\end{array}$ & $\begin{array}{l}\text { MS } \\
\text { MS } \\
\text { MS }\end{array}$ & $\begin{array}{r}50 \\
70 \\
125\end{array}$ & $\begin{array}{l}30 \\
30 \\
40\end{array}$ & $\begin{array}{l}0.8 \\
0.1 \\
0.05\end{array}$ \\
\hline Abdomen (a.p.) & $\begin{array}{l}\text { twice } \\
\text { three times }\end{array}$ & $\begin{array}{r}90 \\
145\end{array}$ & $\begin{array}{l}\text { FS } \\
\text { FS }\end{array}$ & $\begin{array}{l}70 \\
70\end{array}$ & $\begin{array}{l}30 \\
30\end{array}$ & $\begin{array}{l}1.0 \\
1.5\end{array}$ \\
\hline $\begin{array}{l}\text { Lumber spine } \\
\text { (laterally) }\end{array}$ & $\begin{array}{l}\text { twice } \\
\text { three times }\end{array}$ & $\begin{array}{r}90 \\
135\end{array}$ & $\begin{array}{l}\text { HS } \\
\text { SS }\end{array}$ & $\begin{array}{l}70 \\
70\end{array}$ & $\begin{array}{l}30 \\
30\end{array}$ & $\begin{array}{l}1.5 \\
2.0\end{array}$ \\
\hline \multicolumn{7}{|c|}{ TABLE II } \\
\hline
\end{tabular}

\begin{tabular}{|c|c|c|c|c|}
\hline $\mathrm{kV}$ & $\begin{array}{c}\text { Exposure } \\
\text { time }\end{array}$ & Under 0.5 seconds & Under one second & $\begin{array}{l}\text { Under two } \\
\text { seconds }\end{array}$ \\
\hline & 40 & $20(10 \mathrm{ma})$ & $20(10 \mathrm{ma})$ & \multirow{3}{*}{$76(30 \mathrm{ma})$} \\
\hline & 50 & $\left\{\begin{aligned} 79 & (10 \mathrm{ma}) \\
177 & (30 \mathrm{ma})\end{aligned}\right.$ & $\begin{array}{r}10(10 \mathrm{ma}) \\
328(30 \mathrm{ma})\end{array}$ & \\
\hline & 60 & $10(10 \mathrm{ma})$ & $10(10 \mathrm{ma})$ & \\
\hline & 70 & $\left\{\begin{array}{l}10(10 \mathrm{ma}) \\
30(30 \mathrm{ma})\end{array}\right.$ & $\begin{array}{r}10(10 \mathrm{ma}) \\
110(30 \mathrm{ma})\end{array}$ & 40 (30 ma) \\
\hline & & 326 & 488 & $116_{+} \quad 930$ \\
\hline
\end{tabular}

of the focal spot, became distinct, step by step, with the repetition of exposure. There still occurred, however, none of the ruins on the surface of the target up to 930 times exposure as shown in. Fig. 7. Even after the 930 times exposures the resolving power applied to the enlargement radiography of wires of $0.06 \mathrm{~mm}$. in diameter kept constant.

\section{SUMMARY}

This paper is concerned with our very fine focus of a fixed anode tube applied to the enlargement radiography. The focal spot of $0.126 \mathrm{~mm}$. in size, acertained under the geometrical and experimental consideration, was 


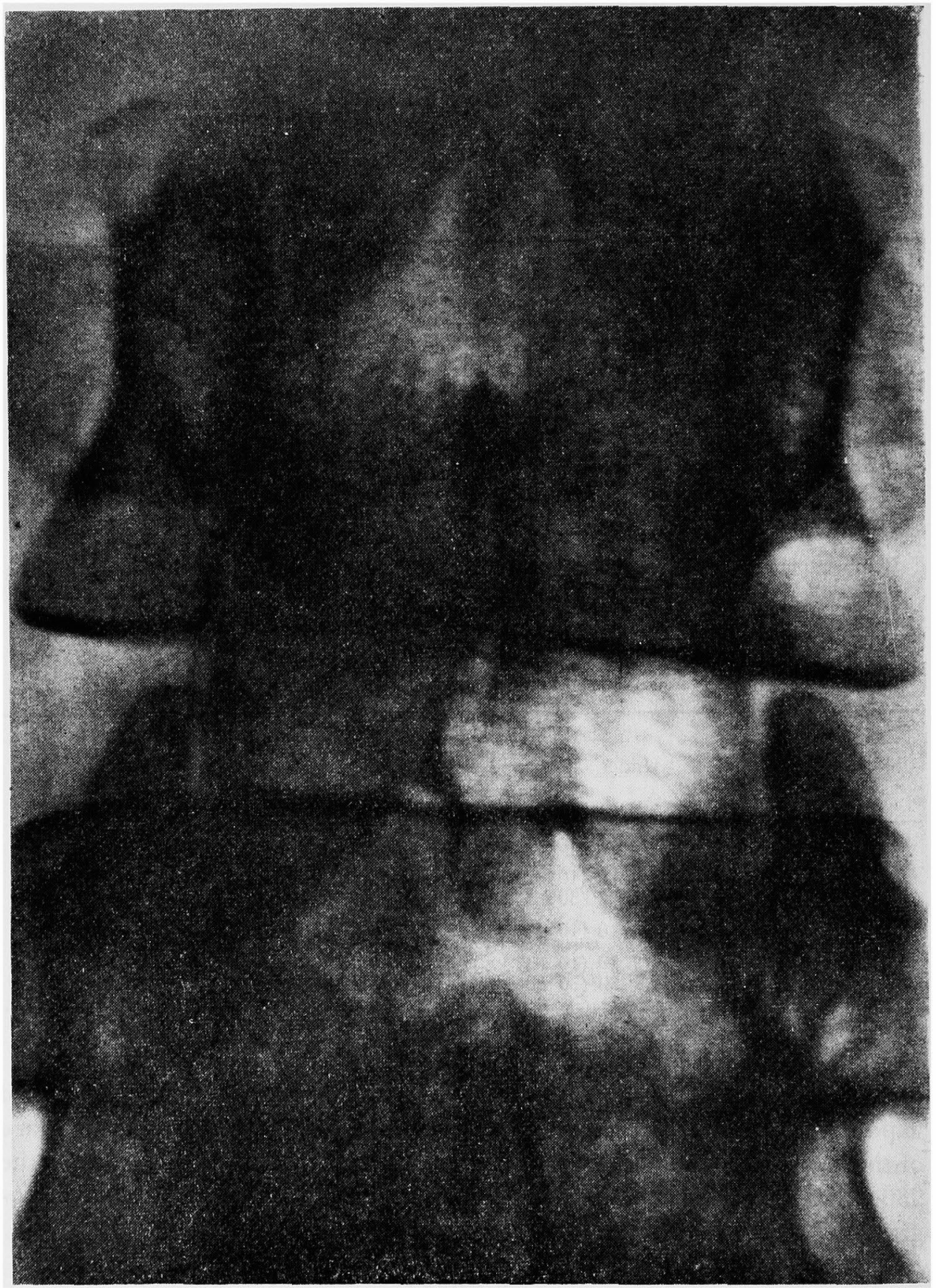

Fig. 6. Enlargement radiogram of the lumbar spine of an adult. (Three times life size) 


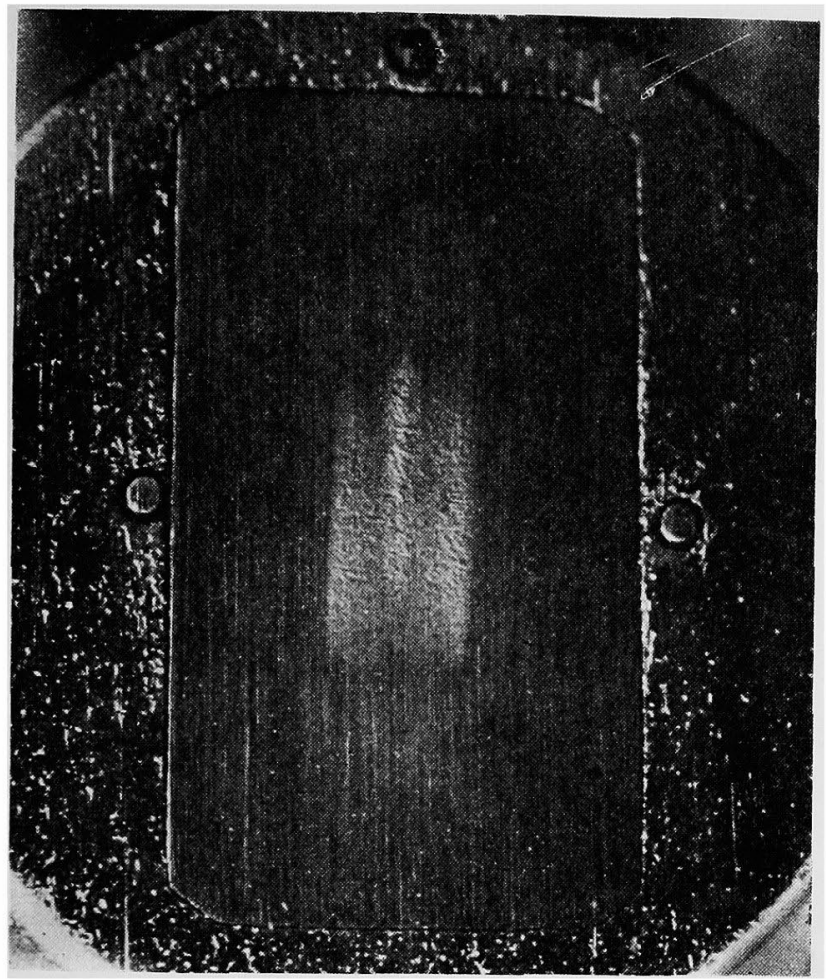

Fig. 7. Target surface of an X-ray tube after 930 times exposure $(3.5$ times enlarged).

made by electron beams narrowed after the principle of bias phenomena. By means of this very fine focus method any part of the body can be taken in sharp enlargement radiogram. Roentgenographic conditions are detailed. Up to now, 930 times exposures were made with this bias tube with no ruin on the surface of the target.

\section{References}

1) Zimmer, Fortschr. Roentgenstr. 1951, 75, 292.

2) Fletcher \& Rowley, Brit J. Radiol. 1951, 24, 598.

3) Wood, Radiology. 1953, 61, 382 .

4) Burger, Combee, \& van der Tunk, Philips Technical Review, 1946, 8, 321. 